\title{
Identification and Characterization of Polyphenols and Volatile Terpenoid Compounds in Different Extracts of Garden Sage (Salvia officinalis L.)
}

\author{
Yashaswini Sharma', Ravikishore Velamuri², John Fagan ${ }^{1,2}$, Jim Schaefer ${ }^{3}$, Christoph Streicher $^{4}$, John Stimson ${ }^{4}$ \\ 'Departments of Sustainable Living, Maharishi University of Management, ${ }^{2}$ Health Research Institute Laboratory, ${ }^{3}$ Soil Technologies Corporation, \\ ${ }^{4}$ Amrita Aromatherapy Inc., Fairfield, lowa, USA
}

\begin{abstract}
Introduction: Garden sage (Salvia officinalis L.) is an important medicinal and aromatic herb, used in various food, pharmaceuticals and cosmetic industries for its potential antioxidant properties. Leaves are the source of essential oils and polyphenols, used as a raw material in food and pharmaceutical industries. Materials and Methods: The study aimed to develop a complete phytochemical profile of $S$. officinalis leaves through liquid chromatography coupled with quadrupole-time of flight mass spectrometry (UHPLC-ESI-OTOF-MS) and gas chromatography with a flame ionization detector (GC-FID). Soxhlet and sonicated extract were analyzed using UHPLC, data-independent acquisition in negative electrospray ionization mode. Essential oil profiling of leaves in comparison with leaves+ stem was carried out using GC-FID. Results: Among the extraction methods, Soxhlet extraction yielded significantly high levels of caffeic acid $(92.45 \pm 1.92 \mu \mathrm{g} / \mathrm{g})$, rosmarinic acid (18821.33 $\pm 150.20 \mu \mathrm{g} / \mathrm{g})$, luteolin-7-glucoside $(635.13 \pm 11.20$ $\mu \mathrm{g} / \mathrm{g})$, carnosic acid $(27.48 \pm 2.37 \mu \mathrm{g} / \mathrm{g})$, carnosol (1347.67 \pm 30.04 $\mu \mathrm{g} / \mathrm{g})$, and ursolic acid $(14938.67 \pm 82.20 \mu \mathrm{g} / \mathrm{g})$. Among the 43 identified phenolic compounds, two flavonoids, diosmetin and pectolinarigenin and two triterpenoids benthamic and micromeric acids have been first time detected in $S$. officinalis leaves. The results of essential oil analysis indicated the presence of $\alpha$-thujone (34.43- $38.93 \%$ ), $\beta$-thujone (6.03-7.58 \%), camphor (15.77-18.12\%), 1,8-cineole (5.45-6.21\%), $\alpha$-humulene $(5.20 \%)$, and camphene $(4.29-5.10 \%)$ as major volatile terpenoid components in S. officinalis. Conclusion: Soxhlet extraction found to be the best method for polyphenol extraction and the essential oil extracted only from leaves best suitable for therapeutic purposes due to less $\alpha$-thujone and $\beta$-thujone content.

Key words: Garden sage, gas chromatography with a flame ionization detector, polyphenols, sonication, Soxhlet extraction, ultra-high-performance liquid chromatography coupled with electrospray ionization quadrupole time-of-flight mass spectrometry
\end{abstract}

\section{SUMMARY}

- UHPLC-ESI-QTOF-MS enabled identification of more than 40 phenolic compounds in sage

- Methanolic extraction of sage yielded high concentration of polyphenols

- Soxhlet extracted samples contained more polyphenols than sonicated samples
- GC-FID analysis of oil resulted in high levels of $\alpha$-thujone, $\beta$-thujone, camphor and 1,8-cineole

- Quality of essential oil from sage leaves better than leaves+ stem oil.

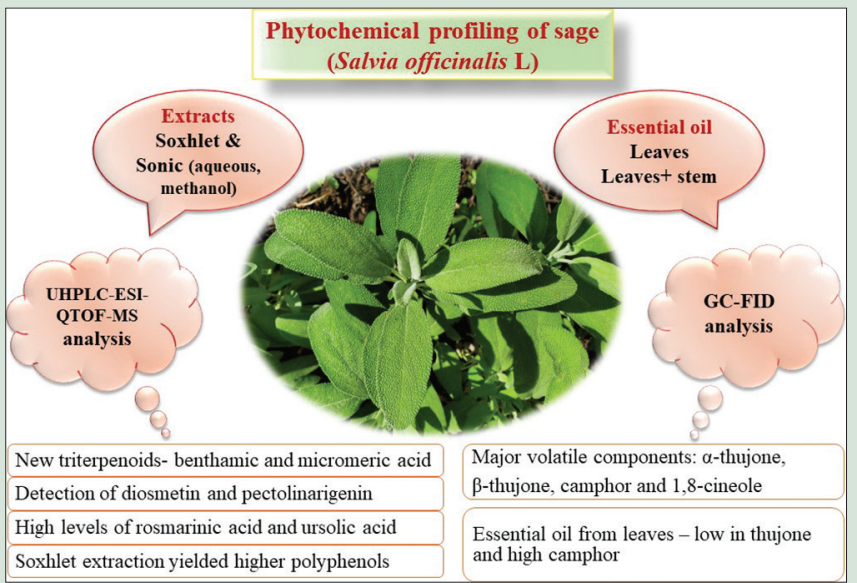

Abbreviations Used: UHPLC-ESI-OTOF-MS: Ultra-High-Performance Liquid Chromatography coupled with Electrospray Ionization, Quadrupole Time-of-Flight Mass Spectrometry; LC-MS: Liquid chromatography-mass spectrometry; SX: Soxhlet extraction (SX); SW: Sonic extraction in water; SM: Sonic extraction in Methanol; NIST: National Institutes of Standards and Technology; AOI: All-in-One; DIA: Data-independent acquisitions; SWATH: Sequential window acquisition of all theoretical fragment-ion spectra; GC-FID: Gas chromatography with a flame ionization detector

Correspondence:

Dr. Yashaswini Sharma,

Department of Sustainable Living,

Maharishi University of Management,

Fairfield, lowa 52557, USA.

E-mail: yashu.vs@gmail.com

DOI: 10.4103/pr.pr_92_19
Access this article online Website: www.phcogres.com

Quick Response Code:

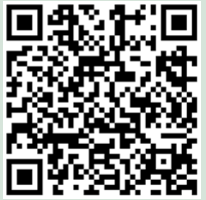

\section{INTRODUCTION}

Salvia officinalis L., popularly known as garden sage or common sage, is a perennial aromatic herb belonging to the family Lamiaceae. It is recognized as a culinary herb in the western world, used in poultry stuffing, flavoring of meat, sausages, and fish. The herb is cultivated for the essential oils present in the leaves and stem, used in perfumes, cosmetics, and pharmaceuticals. ${ }^{[1,2]}$ The herb is used medicinally to improve cognition and to reduce high blood pressure, excessive sweating, nervous disorders, depression, cerebral ischemia, and pharyngitis and also used as an antiseptic. ${ }^{[3,4]}$ S. officinalis leaves are a rich source of polyphenolic compounds with more than 50 identified polyphenols, comprising an
This is an open access journal, and articles are distributed under the terms of the Creative Commons Attribution-NonCommercial-ShareAlike 4.0 License, which allows others to remix, tweak, and build upon the work non-commercially, as long as appropriate credit is given and the new creations are licensed under the identical terms.

For reprints contact: reprints@medknow.com

Cite this article as: Sharma Y, Velamuri R, Fagan J, Schaefer J, Streicher C, Stimson J. Identification and characterization of polyphenols and volatile terpenoid compounds in different extracts of garden sage (Salvia officinalis L.). Phcog Res 2020;12:149-57. 
array of phenolic acids and flavonoids. These phenolic compounds include caffeic acid, rosmarinic acid, salvianolic acids, sagecoumarin, sagerinic acid, and ferulic acid, and the prime flavonoids comprise luteolin, apigenin, hispidulin, kaempferol, and quercetin. ${ }^{[5,6]}$ The majority of the phenolic acids in Salvia species are derivatives of caffeic acid, which occurs mainly in dimeric form as rosmarinic acid. ${ }^{[7]}$ As a natural source of flavonoids and polyphenolic compounds, S. officinalis possesses potent antioxidant, radical-scavenging, and antibacterial activities. ${ }^{[1]} \mathrm{On}$ the other hand, leaves are the source of renewable biomass that could be effectively converted to value-added chemicals, spice, medicine, insecticide, and essential oil. ${ }^{[1,8]}$ Hence, the experiment was planned to study the complete biological efficiency and phytochemical profiling of S. officinalis herb chromatographically.

The conventional technique, Soxhlet extraction (SX) with methanol, has been a widely accepted method to extract the maximum bioactive compounds in herbs. ${ }^{[9]}$ Although it is an efficient method for small-scale laboratory extraction, it is time-consuming and not suitable for heat-labile compounds, besides the residual effect of organic solvents. On the other hand, ultrasound extraction for a shortperiod (1-2h) atlow frequencies $(20$ $\mathrm{kHz}$ ) increases the yield of alkaloids in herbal extracts, which significantly reduces extraction time and solvent consumption. ${ }^{[10,11]}$ Hence, in the present study, S. officinalis leaves were extracted with sonication using water and methanol as solvents, besides SX with methanol. There are few reports on the identification and quantification of phenolic compounds in S. officinalis through liquid chromatography-mass spectrometry (LC-MS), with a limitation of distinguishing the compounds only with unit mass resolution. ${ }^{[5,6]}$ Therefore, the study was conducted to identify and quantify the polyphenols in S. officinalis leaves extracted through Soxhlet apparatus and sonication, by ultra-high-pressure LC, coupled with electrospray ionization quadrupole time-of-flight MS (UHPLC-ESI-QTOF-MS). The UHPLC gives clearly resolved peaks in less time with higher selectivity and sensitivity, and simultaneously, QTOF-MS identifies multiple targeted and untargeted constituents of the sample based on their exact mass $(\mathrm{m} / \mathrm{z})$ and fragmentation pattern with high $\mathrm{m} / \mathrm{z}$ resolution; this technology can even distinguish isobaric compounds by exact mass with different elemental positions. ${ }^{[12,13]}$ On the other hand, gas chromatography with a flame ionization detector (GC-FID) is useful in the analysis of volatile components of the essential oils at trace levels with high sensitivity, stability, and high linear dynamic range. ${ }^{[14,15]}$ Thus, the study also included a GC-FID evaluation of the volatile fraction of essential oil extracted from $S$. officinalis leaves and leaves + stem, mainly to enhance the total biomass content and oil recovery per unit area.

\section{MATERIALS AND METHODS}

\section{Plant material}

S. officinalis herb was grown organically at the Regenerative Organic Farm, the Maharishi University of Management, Fairfield, Iowa, USA, located at $41^{\circ} 01^{\prime}$ Northern latitude, $91^{\circ} 96^{\prime}$ Western longitude with an altitude of $238 \mathrm{~m}$ above mean sea level. Seeds were started in the greenhouse, and the 6-week-old seedlings were transplanted into the field at $45 \mathrm{~cm} \times 30 \mathrm{~cm}$ distance during the $1^{\text {st }}$ week of May. Leaves were harvested in the $2^{\text {nd }}$ week of August, air-dried for 10 days, and powdered for aqueous and methanolic extractions. Leaves along with stem portion leaving $20 \mathrm{~cm}$ from the ground were harvested and cut into 2 " pieces and air-dried for 15 days for essential oil extraction.

\section{Chemicals}

LCMS grade acetonitrile was purchased from Honeywell, Burdick and Jackson, USA, and LCMS grade methanol was purchased from Honeywell, Riedel-de-Haen, USA. LCMS grade formic acid and glacial acetic acid were procured from Merck, Germany. Caffeic acid, rosmarinic acid, carnosic acid, ursolic acid, and luteolin-7-glucoside were purchased from Toronto Research Chemicals, Canada. Carnosol and ${ }^{13} \mathrm{C}$-caffeic acid were purchased from Cayman Chemical, USA. Ultrapure water produced using a Milli-Q; A10 water purification system (Millipore Sigma, USA) was used throughout the experiment.

\section{Preparation of samples for liquid chromatography}

Three extracts were used for LC-MS analysis, Soxhlet methanol extract, and sonic water and methanol extracts.

\section{Soxhlet extraction}

$10 \mathrm{~g}$ of $\mathrm{S}$. officinalis leaf powder was extracted in $250 \mathrm{ml}$ LC-MS grade methanol using the Soxhlet apparatus and at $50^{\circ} \mathrm{C}$ for $6 \mathrm{~h}$ or until we get the clear solvent in the extraction chamber. The extraction was vacuum evaporated and the volume was made up to $100 \mathrm{ml}$, and the extract was then filtered using a $0.2-\mu$ Nalgene filter unit from Thermo Fisher Scientific Inc.

\section{Sonic (ultrasound) extraction with water or methanol}

$10 \mathrm{~g}$ of leaf powder was extracted in $100 \mathrm{ml}$ of distilled water or analytical grade methanol for $2 \mathrm{~h}$ with a frequency of $40 \mathrm{kHz}$ in Bransonic-52 ultrasonic bath unit from Branson, USA. The extract was filtered using a $0.2-\mu$ Nalgene filter and stored.

All extractions were made in triplicate and stored at $-20^{\circ} \mathrm{C}$ until chromatographic analysis.

\section{Identification and quantification of polyphenols by ultra-high-performance liquid chromatography coupled with electrospray ionization with quadrupole time-of-flight mass spectrometry}

The S. officinalis leaf extracts were analyzed using LC coupled with electrospray negative ionization QTOF-MS (UHPLC-ESI-QTOF-MS). The analysis was carried out by reverse-phase UHPLC using a Shimadzu Nexera UHPLC system (Kyoto, Japan) that was directly connected to a QTOF Triple TOF 5600 mass spectrometer (AB SCIEX, Concord, Canada) in direct injection mode. The autosampler (Shimadzu SIL30AC, Kyoto, Japan) was operated in full injection mode filling a $50 \mu$ loop with $10 \mu \mathrm{l}$ analyte for optimal sample delivery reproducibility. Briefly, after injection, sample mixtures were transferred onto the analytical $\mathrm{C}_{18}$ HPLC column (C-18 Kinetex XB, $1 \mathrm{~mm}$ ID $\times 5 \mathrm{~cm}, 2.6 \mu \mathrm{m}$ particle size, $100 \AA$ pore size, Phenomenex, CA, USA) and eluted at a flow rate of $250 \mu \mathrm{l} / \mathrm{min}$. Pumps (Shimadzu LC30AD, Kyoto, Japan) were operated in the following multi-step linear gradient with different proportions of mobile phase B: 0 min, $10 \% \mathrm{~B} ; 10 \mathrm{~min}, 90 \% \mathrm{~B} ; 12.5 \mathrm{~min}, 90 \% \mathrm{~B} ; 15 \mathrm{~min}$, $10 \% \mathrm{~B}$; and $20 \mathrm{~min}, 10 \% \mathrm{~B}$, with a total runtime of $20 \mathrm{~min}$, including mobile phase equilibration. Mobile phases A and B were $0.1 \%$ of acetic acid made in Milli-Q water and acetonitrile, respectively. Column oven (Shimadzu CTO30A, Kyoto, Japan) was set to $40^{\circ} \mathrm{C}$.

\section{Data-independent acquisitions, MS/MS ${ }^{\mathrm{ALL}}$ with SWATH $^{\circ}$ acquisitions}

Mass spectra and tandem mass spectra data were recorded in ESI "negative ion" and "high sensitivity" mode, with a resolution of $\sim 35,000$ full-width half-maximum on the Triple TOF 5600. The ion spray needle voltage was at $-4500 \mathrm{~V}$ with drying gas temperature of $600^{\circ} \mathrm{C}$; ion source Gas 1 (nebulizer) and Gas 2 (heater) values were 50 psi each; curtain gas was $35 \mathrm{psi}$. The collision-energy values for TOF MS were $5 \mathrm{eV}$ and for MS/MS experiments was $25 \mathrm{eV}$, with a spread of $15 \mathrm{eV}$. The sample ions were fragmented using collision gas and nitrogen, and 
the mass range for QTOF-MS was fixed to $\pm 1 \mathrm{~m} / \mathrm{z}$. In the SWATH-MS2 acquisition, a variable SWATH window was used to cover the mass range of $\mathrm{m} / \mathrm{z} 50-1000$ in 16 segments $(15 \mathrm{~ms} \times 48.5 \mathrm{~ms}$ ), yielding a cycle time of $0.8268 \mathrm{~s}$, which includes one $50 \mathrm{~ms}$ MS1 scan. SWATH-MS2 generates multiple MS/MS spectra, a combination of all the analytes in the selected Q1 m/z window. During the execution of the LC method, the mass spectrometer was externally calibrated using a known mixture of masses from Sciex (P/N 4460134, AB SCIEX, Concord, Canada). The mixture was injected at the beginning of each run, and all the spectra were calibrated before compound identification.

Quantitative analysis was performed by diluting the extracted samples with $0.1 \%$ formic acid $(1 / 10-1 / 10,000)$ to quantify the samples within the linearity range of standard calibration curve, avoiding MS signal saturation. Subsequently, the diluted samples were centrifuged at $14,000 \mathrm{rpm}$ for $15 \mathrm{~min}$, and further, the supernatant added with $25 \mu \mathrm{l}$ of the internal standard mixture $\left({ }^{13} \mathrm{C}\right.$ caffeic acid/diclofenac/chloramphenicol). All samples were extracted and analyzed in triplicates. The standard calibration curves $(6-250 \mathrm{ng} / \mathrm{ml})$ for caffeic acid $(y=0.00485 x+0.00658$; $\left.R^{2}=0.9983\right)$, rosmarinic acid $\left(\mathrm{y}=0.03863 \mathrm{x}+0.06813 ; R^{2}=9984\right)$, carnosol $\left(\mathrm{y}=0.05899 \mathrm{x}-0.08327 ; R^{2}=9924\right)$, and luteolin-7-O glucoside $\left(\mathrm{y}=0.03269 \mathrm{x}+0.05975 ; R^{2}=9975\right)$ were constructed for quantification of those compounds. The calibration curve for carnosic acid $\left(y=5.26301 \mathrm{e}-5 \mathrm{x}^{2}+0.00373 \mathrm{x}+0.12615 ; R^{2}=9971\right)$ and ursolic acid $\left(\mathrm{y}=0.01283 \mathrm{x}+0.25563 ; R^{2}=9944\right)$ were created at higher concentration (24-1000 ng/ml) as the MS signal fails to record sensitivity at lower levels. All samples were extracted and analyzed in triplicates. Unknown polyphenolic compounds and flavonoids were identified based on their accurate mass $(\mathrm{m} / \mathrm{z})$ and molecular $(\mathrm{m} / \mathrm{z})$ ion fragmentation using Peak View Software (ver. 2.2, AB SCIEX, Concord, Canada), Master View, Library View (AB SCIEX, Concord, Canada), National Institutes of Standards and Technology (NIST), and AOI database.

\section{Essential oil extraction}

$200 \mathrm{~g}$ of air-dried S. officinalis herb was steam distilled for $120 \mathrm{~min}$ at $100^{\circ} \mathrm{C}$ with a small-scale Clevenger-type apparatus; however, maximum oil recovery was within $90 \mathrm{~min}$, and after that, there was no oil yield. Two different kinds of essential oils were extracted: (1) S. officinalis leaves along with the stem and (2) S. officinalis leaves alone, discarding the stem portion. Steam distilled oil samples were dried on anhydrous sodium sulfate salt and filtered through Whatman grade 5 cellulose filter paper. Filtered oil was stored in amber color glass bottles in a cool, dark place before chemical analysis. All the extractions were carried out in triplicates. Further, the essential oil samples were diluted with n-hexane (Millipore-Merck KGaA, Germany) before chromatographic analysis.

\section{Essential oil analysis of Salvia officinalis}

Essential oil samples of $S$. officinalis were analyzed using GC-FID from Agilent Technology Hewlett Packard 6890 series (USA) connected to DB-5 column coated with 5\% phenyl methyl siloxane (HP-5) having $30 \mathrm{~m} \times 0.25 \mathrm{~mm} \times 0.25 \mu \mathrm{m}$ dimension used for the analysis. The injection volume of $0.2 \mu \mathrm{l}$ diluted essential oil was injected into the capillary GC column. The FID and the injector were maintained at $325^{\circ} \mathrm{C}$ and $250^{\circ} \mathrm{C}$, respectively. Hydrogen was used as the carrier gas, the flow rate through the column was $23.9 \mathrm{ml} / \mathrm{min}$, and the split ratio was set to $20: 1$. The column oven temperature was maintained at $56^{\circ} \mathrm{C}$ initially and then raised to $250^{\circ} \mathrm{C}$ at the rate of $3.1^{\circ} \mathrm{C} / \mathrm{min}$. The run time for each sample was $75 \mathrm{~min}$. Identification of volatile compounds was based on the internal laboratory database developed using authentic compounds as well as pure essential oil samples and Adams data library as a retention time and retention index reference for the DB-5 column using Agilent Chem Station software. ${ }^{[16]}$

\section{Statistical analysis}

The results of polyphenol quantification were expressed as mean \pm standard deviation; the data were analyzed statistically using single-factor ANOVA in MS Excel software. The critical difference at $5 \%$ level of significance or Tukey's honestly significant difference test (at $P<0.05$ ) was used to compare the significant difference between the treatments. ${ }^{[17]}$

\section{RESULTS AND DISCUSSION}

\section{Quantitative analysis of Salvia officinalis leaf extracts}

Phenolic compounds such as caffeic acid, carnosic acid, ursolic acid, rosmarinic acid, carnosol, and luteolin-7-O glucoside were quantified using calibration curves for each of their respective reference standards. Concentrations of phenolic compounds $(\mu \mathrm{g} / \mathrm{g})$ in different extracts of S. officinalis analyzed through UHPLC-ESI-QTOF-MS are presented in Table 1. All three extraction methods, Soxhlet, sonic extraction with water, and methanol, recorded substantial concentrations of phenolic compounds in S. officinalis. Among the extraction methods, SX yielded significantly higher concentrations of caffeic acid $(92.45 \pm 1.92 \mu \mathrm{g} / \mathrm{g})$, rosmarinic acid $(18821.33 \pm 150.20 \mu \mathrm{g} / \mathrm{g})$, luteolin-7-glucoside $(635.13$ $\pm 11.20 \mu \mathrm{g} / \mathrm{g})$, carnosic acid $(27.48 \pm 2.37 \mu \mathrm{g} / \mathrm{g})$, carnosol (1347.67 \pm $30.04 \mu \mathrm{g} / \mathrm{g})$, and ursolic acid $(14938.67 \pm 82.20 \mu \mathrm{g} / \mathrm{g})$. Hot continuous extraction or SX combined with methanol solvent might enhance the solubility of polyphenols, flavonoids, anthocyanins, and other bioactive compounds present in herbs, maximizing the extraction of phenolic compounds. ${ }^{[18]}$ There were only a few studies reported regarding polyphenol analysis and quantification in S. officinalis. ${ }^{[19-22]}$ Hamrouni-Sellami et al. studied the phenolic contents in methanol extracts of $S$. officinalis grown in Tunisia through reverse-phase HPLC and reported much less concentration of phenolic acids, caffeic acid (44.37 $\mu \mathrm{g} / \mathrm{g})$, rosmarinic acid $(110.6 \mu \mathrm{g} / \mathrm{g})$, luteolin $8.11 \mu \mathrm{g} / \mathrm{g})$, and carnosol $(2.07 \mu \mathrm{g} / \mathrm{g})$ as compared to the present study. ${ }^{[23]}$

Ultrasound extraction in methanol exhibited significantly higher concentrations of carnosic acid, ursolic acid, rosmarinic acid, carnosol, and luteolin-7-O glucoside than the aqueous sonicated samples. Ultrasound is known to disrupt plant cell walls, thereby facilitating the release of extractable compounds and enhancing mass transport of solvent from the continuous phase into plant cells, and this effect boosts recovery of polyphenols, especially when optimal solvent, such as methanol, is used. ${ }^{[1,24]}$ S. officinalis leaf extracted by sonication using water as solvent yielded the lowest phenolic acid and flavonoid content, compared to sonication and SX with methanol. Phenolic compounds are known to form complex molecules that are insoluble in an aqueous base. ${ }^{[25]}$ Ultrasonically assisted solvent extraction reported to be more efficient, and ultrasonic extraction in water-based media was compared with herbal decoction process. ${ }^{[11]}$ Hence, in the current study, the efficacy of methanol sonic extraction was more than the aqueous extraction. In the present investigation, the caffeic acid concentration in sonicated methanol (SM) and aqueous extracts (SW) was similar, which likely reflects the solubility of caffeic acid in both water and methanol. Lower rosmarinic acid levels in aqueous $S$. officinalis extracts were reported by Kontogianni et al. while working with different solvents for the herb extraction process. ${ }^{[26]}$ The significantly higher concentrations of rosmarinic and ursolic acid [10.8-18.8 mg/g and 1.1-14.9 mg/g, respectively, Table 1], measured in the methanolic extracts prepared in this study, demonstrate that $S$. officinalis is a high-quality source of these compounds, which are useful for treatment of an array of diseases, including gastrointestinal inflammation, colitis, colon cancer, and nervous system inflammation. ${ }^{[27]}$ 


\section{Qualitative analysis of Salvia officinalis leaf extracts}

Most of the qualitative analysis of phenolic compounds in garden sage was reported either by HPLC or high performance liquid chromatography with diode array detector (HPLC-DAD) based on their retention time, ultraviolet-visible, and mass spectra. ${ }^{[19,23]}$ The high resolution, accurate mass, UHPLC-ESI-QTOF-MS analysis used in this study facilitated even more in-depth identification and characterization of known and previously unknown compounds based on their molecular formulae, exact mass measurements, and MS/MS fragmentation patterns. ${ }^{[28]}$ In the present study, negative ionization mode $[\mathrm{M}-\mathrm{H}]^{-}$was used because it was reported to be more sensitive for analysis of phenolic acids and flavonoids as compared to positive ionization mode. ${ }^{[28-30]}$ Several polyphenolic compounds present in S. officinalis leaf extracts have been identified using UHPLC-ESI-QTOF-MS under negative ESI conditions $[\mathrm{M}-\mathrm{H}]^{-}$along with retention time, molecular weight, and mass $(\mathrm{m} / \mathrm{z})$ fragmentation pattern. These results are presented in Table 2. The compounds without reference standards were identified tentatively by comparing the mass spectra data, ion fragmentation, and molecular weight $(\mathrm{m} / \mathrm{z})$ with data available in the literature as well as mass spectral library obtained from the NIST. ${ }^{[19,31]}$

As shown in Table 2, 43 different phenolic compounds have been identified, including phenolic acids, flavonoids, and terpenoids in three extracts of S. officinalis. All three extracts contained various polyphenols, and among them, two flavonoid compounds, diosmetin ([M-H $]^{-}$ $\mathrm{m} / \mathrm{z}$ 299.05) and pectolinarigenin ([M-H $]^{-} \mathrm{m} / \mathrm{z}$ 313.07), have been identified for the first time in $S$. officinalis leaf extracts that we have prepared. Diosmetin and pectolinarigenin, previously found in other herbs, are reported to have potent anti-inflammatory and anticancer properties. ${ }^{[32,33]}$ The two new triterpenoids, benthamic acid $\left([\mathrm{M}-\mathrm{H}]^{-} \mathrm{m} / \mathrm{z}\right.$ 471.34) and micromeric acid $\left([\mathrm{M}-\mathrm{H}]^{-} \mathrm{m} / \mathrm{z} 453.33\right)$, are also reported here for the first time to be detected by QTOF-MS in S. officinalis leaves. Phenolic acids, namely caffeic acid $\left([\mathrm{M}-\mathrm{H}]^{-} \mathrm{m} / \mathrm{z} 179.04\right)$, ferulic acid $\left([\mathrm{M}-\mathrm{H}]^{-} \mathrm{m} / \mathrm{z}\right.$ 193.05), rosmarinic acid $\left([\mathrm{M}-\mathrm{H}]^{-} \mathrm{m} / \mathrm{z} 359.08\right)$, and sagerinic acid $\left([\mathrm{M}-\mathrm{H}]^{-} \mathrm{m} / \mathrm{z} 719.16\right)$, were detected in all three $S$. officinalis extracts. Danshensu $\left([\mathrm{M}-\mathrm{H}]^{-}\right.$at $\mathrm{m} / \mathrm{z}$ 197.05) and scutellarin $\left([\mathrm{M}-\mathrm{H}]^{-}\right.$at $\mathrm{m} / \mathrm{z}$ 461.07) were identified only in sonic extracts with methanol. These identities were confirmed as danshensu by comparison with the $\mathrm{m} / \mathrm{z}$ ion fragmentation pattern $(135.0450,123.0450,72.9947$, and 179.0349) in the NIST MS library and previous literature data. ${ }^{[22]}$ Danshensu $\left([\mathrm{M}-\mathrm{H}]^{-}\right.$ at $\mathrm{m} / \mathrm{z} 197.05)$, caffeic acid 3-glucoside $\left([\mathrm{M}-\mathrm{H}]^{-}\right.$at $\left.\mathrm{m} / \mathrm{z} 341.09\right)$, ferulic acid $\left([\mathrm{M}-\mathrm{H}]^{-}\right.$at $\left.\mathrm{m} / \mathrm{z} 193.95\right)$, rosmarinic acid $\left([\mathrm{M}-\mathrm{H}]^{-}\right.$at $\left.\mathrm{m} / \mathrm{z} 359.08\right)$, and methyl rosmarinate $\left([\mathrm{M}-\mathrm{H}]^{-}\right.$at $\mathrm{m} / \mathrm{z}$ 373.09), all shared many of the same MS/MS $(\mathrm{m} / \mathrm{z})$ ion fragments (179.03), since they are all structurally related to caffeic acid. Many phenolic acids of Salvia species were previously reported to be caffeic acid derivatives, mostly formed by esterification of caffeic acid with danshensu. ${ }^{[34]}$ The phenolic acids derived from caffeic acid were also extensively reported in polyphenol studies of S. officinalis. ${ }^{[5,22,35]}$ Similarly, sagerinic acid $\left([\mathrm{M}-\mathrm{H}]^{-} \mathrm{m} / \mathrm{z}\right.$ 719.16) and salvianolic acid $\mathrm{L}\left([\mathrm{M}-\mathrm{H}]^{-} \mathrm{m} / \mathrm{z} 717.14\right)$ were also found to share similar $(\mathrm{m} / \mathrm{z}) \mathrm{MS} / \mathrm{MS}$ ion fragments (359.07) as they derive from rosmarinic acid $\left([\mathrm{M}-\mathrm{H}]^{-} \mathrm{m} / \mathrm{z}\right.$ 359.08). Lu and Foo reported sagerinic acid and salvianolic acid to be dimers of rosmarinic acid with a potent phenolic antioxidant activity in S. officinalis. ${ }^{[36]}$

Methanol was found to be highly efficient in extracting the polyphenols, flavonoids, phenolic acids, and terpenoid compounds from $S$. officinalis leaves than aqueous extraction. The important flavonoids present in all the extracts of $S$. officinalis were gallocatechin $\left([\mathrm{M}-\mathrm{H}]^{-} \mathrm{m} / \mathrm{z} \text { 305.07), luteolin-7-O-glucoside ([M-H }\right]^{-}$ $\mathrm{m} / \mathrm{z}$ 447.09), isorhamnetin-3-glucoside $\left([\mathrm{M}-\mathrm{H}]^{-} \mathrm{m} / \mathrm{z} 477.10\right)$, hispidulin glucuronide $\left([\mathrm{M}-\mathrm{H}]^{-} \mathrm{m} / \mathrm{z}\right.$ 175.09), apigenin-7-glucuronide $\left([\mathrm{M}-\mathrm{H}]^{-} \mathrm{m} / \mathrm{z}\right.$ 445.08), and homoplantaginin $\left([\mathrm{M}-\mathrm{H}]^{-} \mathrm{m} / \mathrm{z}\right.$ 461.11). However, apigenin, diosmetin, and pectolinarigenin flavonoids were identified only in methanolic samples. Phenolic diterpenoids such as rosmanol, rosmadial, carnosol, and carnosic acids were also identified in all the $S$. officinalis extracts. However, the phenolic triterpenoid compounds such as asiatic acid, benthamic acid, micromeric acid, and ursolic acids were detected only in methanolic samples. A triterpenoid compound, betulinic acid

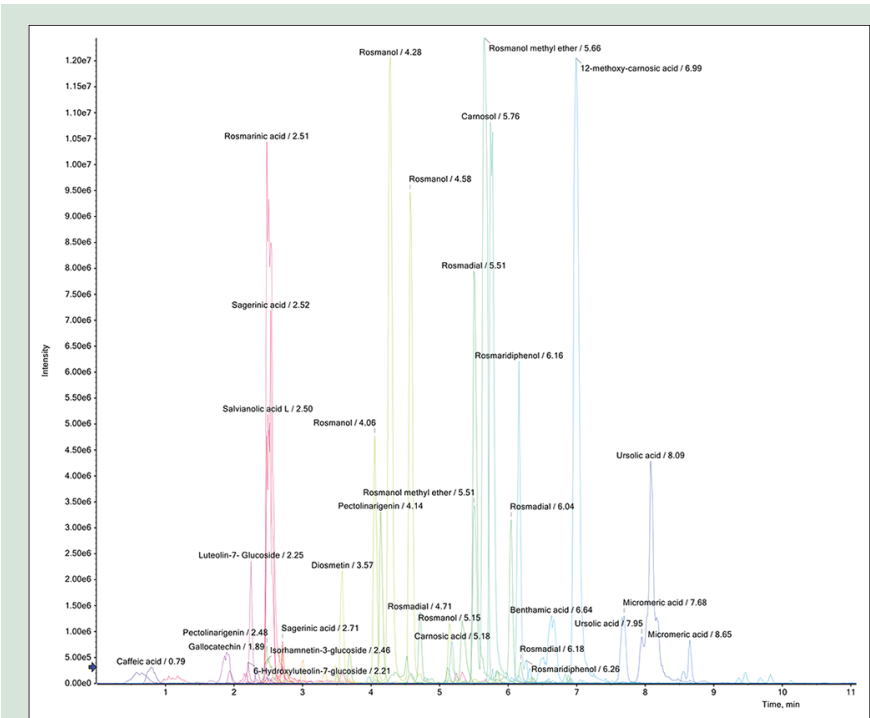

Figure 1: The relative abundance of phenolic compounds in sage leaves - Soxhlet extraction analyzed through ultra-high-performance liquid chromatography coupled electrospray ionization quadrupole time-of-flight mass spectrometry (intensity of phenolic compounds vs. elution time)

Table 1: Concentrations of phenolic compounds $(\mu \mathrm{g} / \mathrm{g})$ in different extraction of Salvia officinalis analyzed through ultra-high-pressure liquid chromatography, electrospray ionization, coupled with quadrupole time-of-flight mass spectrometry

\begin{tabular}{|c|c|c|c|c|c|c|}
\hline & \multicolumn{6}{|c|}{ Polyphenol content $(\mu \mathrm{g} / \mathrm{g})$ in sage } \\
\hline & Caffeic acid & Rosmarinic acid & Luteolon-7-glucoside & Carnosic acid & Carnosol & Ursolic acid \\
\hline \multicolumn{7}{|l|}{ Extract } \\
\hline Soxhlet & $92.45 \pm 1.92^{\mathrm{b}}$ & $18,821 \cdot 33 \pm 150.20^{c}$ & $635.13 \pm 11.20^{c}$ & $27.48 \pm 2.37^{c}$ & $1347.67 \pm 30.04^{c}$ & $14,938 \cdot 67 \pm 82.20^{c}$ \\
\hline Sonication-water & $73.24 \pm 1.62^{\mathrm{a}}$ & $67.41 \pm 2.03^{\mathrm{a}}$ & $53.25 \pm 3.66^{\mathrm{a}}$ & $1.79 \pm 0.38^{\mathrm{a}}$ & $6.10 \pm 0.60^{a}$ & $0.72 \pm 0.04^{\mathrm{a}}$ \\
\hline Sonication-methanol & $73.86 \pm 1.84^{\mathrm{a}}$ & $10,874.67 \pm 53.45^{\mathrm{b}}$ & $304.27 \pm 6.60^{\mathrm{b}}$ & $12.68 \pm 1.10^{\mathrm{b}}$ & $537.60 \pm 17.20^{\mathrm{b}}$ & $1098.67 \pm 16.23^{b}$ \\
\hline Mean & 79.85 & 9921.14 & 330.88 & 13.98 & 630.45 & 5346.02 \\
\hline$F$ test & $* *$ & ** & $* *$ & $* *$ & ** & ** \\
\hline SEM \pm & 1.04 & 53.15 & 4.50 & 0.88 & 11.54 & 27.93 \\
\hline $\mathrm{CD}$ at $5 \%$ & 3.59 & 183.92 & 15.58 & 3.04 & 39.93 & 96.65 \\
\hline
\end{tabular}

** Significant at $5 \%$ level, values followed by different letters indicate a significant difference between the treatments at $P<0.05$. SEM: Standard error of the mean; CD: Critical difference 
Table 2: Polyphenolic compounds in different Salvia officinalis leaf extracts identified by liquid chromatography tandem-mass spectrometry (ultra-high-pressure liquid chromatography, electrospray ionization coupled with quadrupole time-of-flight mass spectrometry)

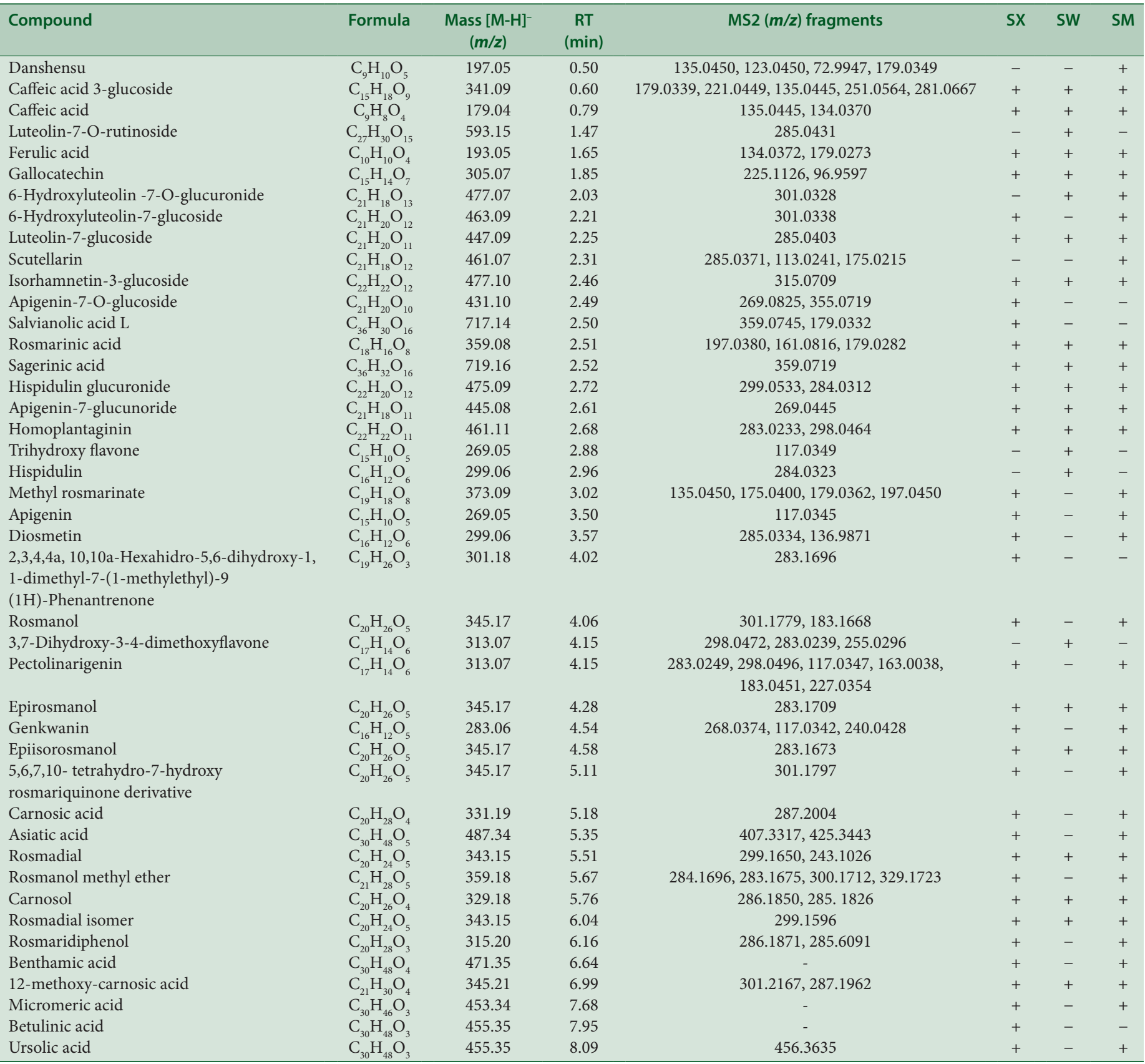

SX: Soxhlet; SW: Sonication with water; SM: Sonication with methanol; +: Detected in the sample; -: Not detected in the sample; RT: Retention time

with a pseudomolecular weight $[\mathrm{M}-\mathrm{H}]^{-}$at $\mathrm{m} / \mathrm{z} 455.35$, was detected only in Soxhlet-extracted samples of $S$. officinalis. Even though ursolic acid and betulinic acid have the same pseudomolecular weight $\left([\mathrm{M}-\mathrm{H}]^{-}\right.$at $\mathrm{m} / \mathrm{z} 455.35)$, the former was identified through the reference standard while the later molecule was confirmed by comparison to the NIST mass spectral library.

The relative abundance of identified phenolic compounds in SX, sonication with water, and methanol is presented in Figures 1-3, respectively, reflecting the relative efficiencies of these methods for recovery of various compounds from S. officinalis. In SX, besides rosmarinic acid, rosmanol, rosmanol methyl ether, rosmadial, 12-methoxy carnosic acid, sagerinic acid, and salvianolic acid L. were also found in abundance [Figure 1]. The high intensity of pentacyclic triterpenoids, ursolic acid, benthamic acid, and micromeric acid, was recorded in methanolic extracts of S. officinalis. Presence of more than one peak corresponding to the same molecular mass but different elution times was due to the presence of isomers, such as rosmanol, rosmadial, sagerinic acid, and pectolinarigenin. Rosmanol $\left([\mathrm{M}-\mathrm{H}]^{-} \mathrm{m} / \mathrm{z} 345.17\right)$ recorded three peaks at $4.06,4.28$, and $4.58 \mathrm{~min}$, representing rosmanol $\left(\mathrm{MS}^{2} \mathrm{~m} / \mathrm{z}\right.$ fragments 301.1779, 183.1668), epirosmanol $\left(\mathrm{MS}^{2} \mathrm{~m} / \mathrm{z}\right.$ fragment 283.17), and epiisorosmanol $\left(\mathrm{MS}^{2} \mathrm{~m} / \mathrm{z}\right.$ fragment 283.17), respectively [Figures 1 and 3]. There were two clear peaks observed for the rosmadial molecule $\left([\mathrm{M}-\mathrm{H}]^{-}\right.$ $\mathrm{m} / \mathrm{z} 343.15)$ at $5.51 \mathrm{~min}\left(\mathrm{MS}^{2} \mathrm{~m} / \mathrm{z} 299.1650,243.1026\right)$ and $6.04 \mathrm{~min}$ $\left(\mathrm{MS}^{2} \mathrm{~m} / \mathrm{z}\right.$ 299.1596) with similar fragmentation patterns characteristic of this molecule. Similar results were obtained during the 


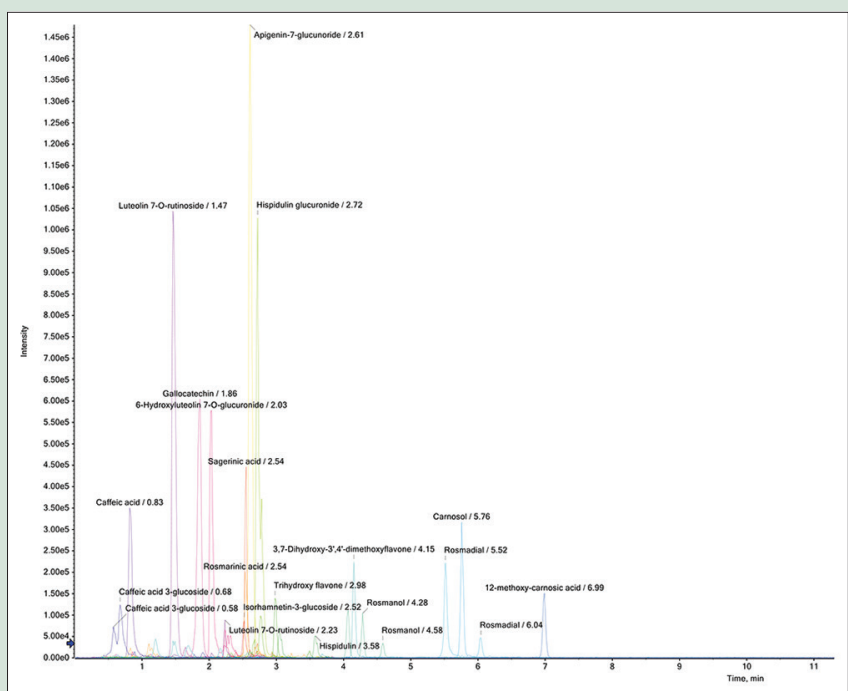

Figure 2: The intensity of phenolic compounds in sage leaves extracted by sonication with water, analyzed through ultra-high-performance liquid chromatography coupled electrospray ionization quadrupole time-of-flight mass spectrometry (intensity vs. elution time) chromatographic determination of polyphenols in aqueous infusions of sage tea, where Zimmermann et al. observed 4-5 peaks of rosmanol and carnosol with similar $\mathrm{m} / \mathrm{z}$ fragmentation patterns. ${ }^{[22]}$

The chromatogram pattern of Soxhlet-extracted samples and SM samples were similar, and the relative abundance of phenolic compounds in both extracts mostly matches with each other, even though the intensity of phenolic compounds in SX was higher [Figures 1 and 3]. There was a similar number of phenolic compounds detected in methanol extracts of $S$. officinalis produced by both Soxhlet and ultrasound procedures. Exposure of samples to high temperatures for an extended period using an optimal solvent, such as methanol, in SX and the acoustic cavitation effect of ultrasound, both increase the permeability of cell walls and enhance the release of compounds in the extract. ${ }^{[10,37]}$ However, it was clear that yields with SX were higher as compared to sonicated extracts. This might be due to increasing extraction efficiency with an increase in time and solvent volume. ${ }^{[38]}$ Even though the SX yielded maximum polyphenols, the extraction process took a long time and consumed a large volume of methanol.

Analysis of $S$. officinalis sonication extract in water revealed high concentrations of conjugated polyphenols, including apigenin-7-glucuronide, hispidulin glucuronide, luteolin 7-O-rutinoside, 6-hydroxyleteolin 7-O-glucuronide, and sagerinic acid [Figure 2]. These were present at proportionately higher levels in the aqueous extracts, presumably because conjugation increases the water solubility of polyphenols. In general, the same phenolic compounds were present in the aqueous extracts as those found in methanol extracts; however, the relative amounts of the compounds were different, probably due to differences in solubility in water versus methanol. Further, in general, the levels of phenolic compounds were substantially lower in aqueous, as compared to methanol extracts. The higher solubility of complex phenolic compounds in organic solvents has been previously noted. ${ }^{[25,39,40]}$

High-resolution and accurate mass LC-MS/MS chromatograms contain comprehensive information of all molecules present in the sample that are amenable to the ionization technique and polarity used. We used mass spectral library searching used to identify non-targeted compounds based on their mass spectral fragmentation pattern. This strategy of identifying compounds based on their molecular

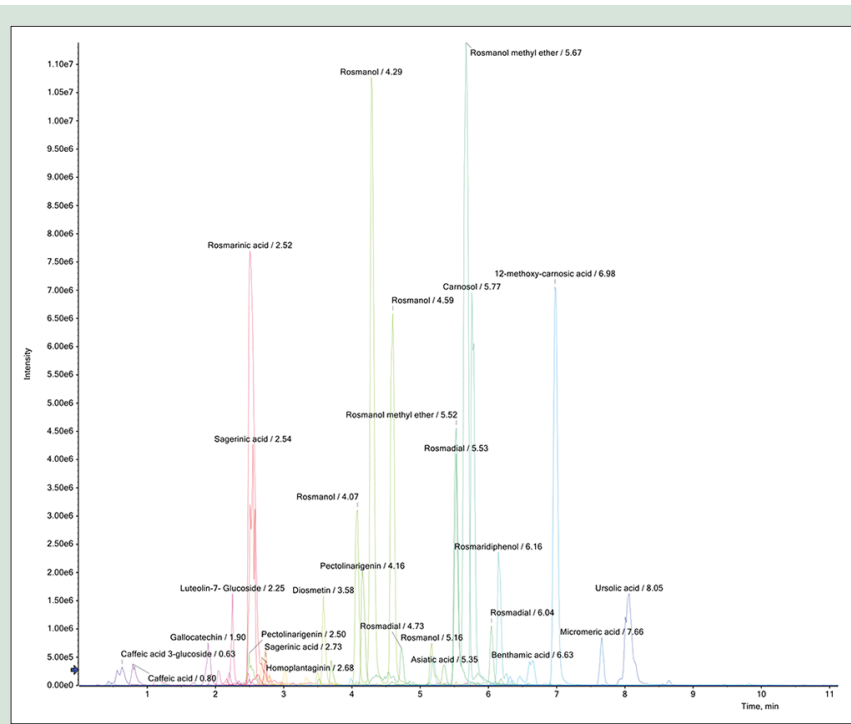

Figure 3: The concentration of phenolic compounds in sage leaves extracted by sonication with methanol, analyzed through ultra-high-performance liquid chromatography coupled electrospray ionization quadrupole time-of-flight mass spectrometry (intensity vs. elution time)

fragmentation fingerprint is very useful and very powerful but is limited to the compounds present in the MS/MS libraries available. Using this methodology, we found that the three different $S$. officinalis extracts that we prepared contained a vast number of polyphenols, of which only a relative few are present in currently available mass spectral libraries and therefore capable of being named in the present study. Thus, there are many yet-unidentified phenolic compounds observed in the mass spectral datasets of the $S$. officinalis extracts we generated using the SWATH untargeted analytical protocol. Indeed, more compounds were detected but remain unidentified than were identified based on the existing mass spectral libraries. As additional mass spectral libraries become available, the datasets that we have generated and others can be analyzed further to identify and characterize many more additional polyphenols based on $\mathrm{m} / \mathrm{z}$ fragmentation patterns.

\section{Essential oil profiling through gas chromatography coupled with flame ionization detector}

Steam distillation of S. officinalis leaves yielded $1.30 \%$ of essential oil and distillation of leaves along with stem yielded $1.25 \%$ of oil on a dry weight basis. The fresh-to-dry conversion ratio of the herb was 33\%. As per the available literature, essential oil content in S. officinalis has been found to vary from $1.1 \%$ to $2.8 \%$ depending on the cultivar, soil, and the weather conditions during the crop growth. ${ }^{[41,42]}$

Analysis of volatile components present in the essential oil by GC-FID is presented in Table 3. The analysis resulted in the separation of 38 volatile terpenoid compounds accounting for $99.47 \%$ and $99.49 \%$ of the oil composition extracted from $S$. officinalis leaves + stem and leaves, respectively. Oxygenated monoterpene content was slightly higher $(71.78 \%)$ in leaves + stem oil as compared to leaf oil $(69.43 \%)$, especially monoterpene ketones. Essential oils with a high level of monoterpene ketones have been reported to exhibit strong antioxidant activity. ${ }^{[43]}$ On the other hand, S. officinalis leaf oil was found to have more sesquiterpenoids and diterpenoid content, indicating the presence of higher molecular weight components that make the oil more stable with an enduring flavor. The mirror image of GC-FID analysis of 
Table 3: Volatile terpenoid compounds in Salvia officinalis essential oil extracted from leaves + stem and leaves analyzed through gas chromatography with a flame ionization detector

\begin{tabular}{|c|c|c|c|c|c|}
\hline \multirow[t]{2}{*}{ Compound } & \multirow[t]{2}{*}{ RT } & \multirow[t]{2}{*}{ RI } & \multirow[t]{2}{*}{ Formula } & \multicolumn{2}{|c|}{ Area \% } \\
\hline & & & & Leaves + stem & Leaves \\
\hline cis-Salvene & 4.16 & 847 & $\mathrm{C}_{9} \mathrm{H}_{16}$ & 0.62 & 0.73 \\
\hline Trans-salvene & 4.35 & 858 & $\mathrm{C}_{9} \mathrm{H}_{16}$ & 0.09 & 0.11 \\
\hline Tricyclene & 5.76 & 921 & $\mathrm{C}_{10}^{9} \mathrm{H}_{16}^{16}$ & 0.13 & 0.14 \\
\hline a-thujene & 5.87 & 924 & $\mathrm{C}_{10}^{10} \mathrm{H}_{16}^{16}$ & 0.31 & 0.25 \\
\hline a-pinene & 6.07 & 932 & $\mathrm{C}_{10}^{10} \mathrm{H}_{16}$ & 2.34 & 3.30 \\
\hline Camphene & 6.48 & 946 & $\mathrm{C}_{10} \mathrm{H}_{16}$ & 4.29 & 5.10 \\
\hline Sabinene & 7.19 & 969 & $\mathrm{C}_{10} \mathrm{H}_{16}$ & 0.36 & 0.19 \\
\hline$\beta$-Pinene & 7.30 & 974 & $\mathrm{C}_{10} \mathrm{H}_{16}$ & 2.55 & 1.91 \\
\hline Myrcene & 7.71 & 988 & $\mathrm{C}_{10} \mathrm{H}_{16}$ & 1.30 & 1.37 \\
\hline a-Phellandrene & 8.15 & 1002 & $\mathrm{C}_{10}^{10} \mathrm{H}_{16}$ & 0.05 & 0.06 \\
\hline$\alpha$-Terpinene & 8.56 & 1014 & $\mathrm{C}_{10} \mathrm{H}_{16}$ & 0.15 & 0.20 \\
\hline p-Cymene & 8.82 & 1020 & $\mathrm{C}_{10} \mathrm{H}_{14}$ & 0.39 & 0.36 \\
\hline d-limonene & 8.98 & 1024 & $\mathrm{C}_{10} \mathrm{H}_{16}^{14}$ & 1.77 & 2.28 \\
\hline 1,8 cineol & 9.06 & 1026 & $\mathrm{C}_{10} \mathrm{H}_{18} \mathrm{O}$ & 5.45 & 6.21 \\
\hline cis- $\beta$ ocimene & 9.29 & 1044 & $\mathrm{C}_{10} \mathrm{H}_{16}$ & 0.07 & 0.06 \\
\hline$\gamma$-Terpinene & 10.04 & 1054 & $\mathrm{C}_{10}^{10^{-1}} \mathrm{H}_{16}^{16}$ & 0.38 & 0.44 \\
\hline cis-Sabinene hydrate & 10.34 & 1065 & $\mathrm{C}_{10} \mathrm{H}_{18} \mathrm{H}^{16} \mathrm{O}$ & 0.20 & 0.14 \\
\hline Terpinolene & 11.14 & 1086 & $\mathrm{C}_{10}^{10} \mathrm{H}_{16}$ & 0.36 & 0.45 \\
\hline Linalool & 11.65 & 1095 & $\mathrm{C}_{10} \mathrm{H}_{18} \mathrm{O}$ & 0.27 & 0.32 \\
\hline$a$-Thujone & 11.87 & 1101 & $\mathrm{C}_{10} \mathrm{H}_{16} \mathrm{O}$ & 38.93 & 34.43 \\
\hline$\beta$-Thujone & 12.23 & 1112 & $\mathrm{C}_{10}^{10} \mathrm{H}_{16} \mathrm{O}$ & 7.58 & 6.03 \\
\hline Trans-sabinol & 13.16 & 1137 & $\mathrm{C}_{10} \mathrm{H}_{16} \mathrm{O}^{16} \mathrm{O}$ & 0.12 & 0.15 \\
\hline Camphor & 13.31 & 1141 & $\mathrm{C}_{10}^{10^{-}} \mathrm{H}_{16} \mathrm{O}$ & 15.77 & 18.12 \\
\hline Neo-iso-3-thujanol & 13.91 & 1147 & $\mathrm{C}_{10} \mathrm{H}_{18} \mathrm{O}$ & 0.15 & 0.06 \\
\hline Borneol & 14.13 & 1165 & $\mathrm{C}_{10} \mathrm{H}_{18} \mathrm{O}$ & 1.76 & 2.13 \\
\hline terpin-4-ol & 14.60 & 1174 & $\mathrm{C}_{10} \mathrm{H}_{18} \mathrm{O}$ & 0.28 & 0.26 \\
\hline$\alpha$-Terpineol & 15.14 & 1186 & $\mathrm{C}_{10} \mathrm{H}_{18} \mathrm{O}$ & 0.10 & 0.13 \\
\hline Myrtenol & 15.37 & 1194 & $\mathrm{C}_{10}^{10} \mathrm{H}_{16}^{18} \mathrm{O}$ & 0.15 & 0.11 \\
\hline Bornyl acetate & 18.98 & 1284 & $\mathrm{C}_{12}^{10} \mathrm{H}_{20}^{16} \mathrm{O}_{2}$ & 0.78 & 1.09 \\
\hline 3-Thujanol acetate & 19.27 & 1295 & $\mathrm{C}_{12}^{12} \mathrm{H}_{20}^{20} \mathrm{O}_{2}^{2}$ & 0.24 & 0.25 \\
\hline$\beta$-Caryophyllene & 24.23 & 1417 & $\mathrm{C}_{15} \mathrm{H}_{24}$ & 3.67 & 3.20 \\
\hline Aromadendrene & 24.88 & 1439 & $\mathrm{C}_{15} \mathrm{H}_{24}$ & 0.10 & 0.19 \\
\hline a-Humulene & 25.53 & 1452 & $\mathrm{C}_{15}^{15} \mathrm{H}_{24}^{24}$ & 5.21 & 5.20 \\
\hline Germacrene A & 27.09 & 1508 & $\mathrm{C}_{15}^{13} \mathrm{H}_{24}^{24}$ & 0.12 & 0.14 \\
\hline Caryophyllene oxide & 30.24 & 1582 & $\mathrm{C}_{15} \mathrm{H}_{24} \mathrm{O}$ & 0.27 & 0.29 \\
\hline Viridiflorol & 30.58 & 1592 & $\mathrm{C}_{15} \mathrm{H}_{26}^{24} \mathrm{O}$ & 2.17 & 2.42 \\
\hline Humulene epoxide II & 31.18 & 1608 & $\mathrm{C}_{15}^{15} \mathrm{H}_{24}^{26} \mathrm{O}$ & 0.38 & 0.56 \\
\hline Manool oxide & 45.32 & 1987 & $\mathrm{C}_{20} \mathrm{H}_{34}^{24} \mathrm{O}$ & 0.61 & 1.11 \\
\hline Identification of total c & & & & 99.47 & 99.49 \\
\hline Normonoterpenes & & & & 0.71 & 0.84 \\
\hline Monoterpenes & & & & 14.45 & 16.11 \\
\hline Oxygenated monoterp & & & & 71.78 & 69.43 \\
\hline Monoterpene alcoho & & & & 8.48 & 9.51 \\
\hline Monoterpene ketone & & & & 62.28 & 58.58 \\
\hline Monoterpene esters & & & & 1.02 & 1.34 \\
\hline Sesquiterpenes & & & & 11.92 & 12.00 \\
\hline Diterpenes & & & & 0.61 & 1.11 \\
\hline
\end{tabular}

RT: Retention time; RI: Retention indices for DB-5 column

S. officinalis essential oil from leaves + stem and only from leaves with the relative abundance of volatile compounds against retention time is depicted in Figure 4. Both sage leaves + stem and leaf essential oil were characterized by high $\alpha$-thujone $(34.43 \%-38.93 \%), \beta$-thujone (6.03\%-7.58\%), camphor (15.77\%-18.12\%), 1,8-cineole (5.45\%-6.21\%), $\alpha$-humulene (5.20\%), and camphene (4.29\%-5.10\%). A similar composition with elevated thujone levels was reported in sage grown in Poland and Brazil. ${ }^{[8,42,44]}$ However, some essential oil of sage from Egypt and Tunisia also recorded higher camphor content (23\%-26\%), almost equal to $\alpha$-thujone content. ${ }^{[45,46]}$

Even though the oil content from leaves and leaves + stem was almost same, the oil yield per unit area was more in leaves + stem. However, as compared to $S$. officinalis leaves + stem oil, leaf oil was found to be safer and of finer quality as the later contained less thujone. $\alpha$-thujone reported to be toxic on the brain, liver, and kidney cells and might cause convulsions by consumption of sage essential oils rich in thujone content. ${ }^{[47,48]}$ The comparatively high concentration of toxic thujones seems to be characteristic of sage leaves cultivated in different locations as well. ${ }^{[49,50]}$ Hence, the leaf oil could be used for therapeutic purpose whereas leaves + stem oil might be used as an effective insecticide. Studies have also shown that therapeutic properties sage depends on camphor, 1,8-cineole, $\alpha$-thujone, and $\beta$-thujone content. The essential oil of $S$. officinalis analyzed in the present study also recorded high camphor and 1,8-cineole, which are known to enhance radical scavenging activities of essential. ${ }^{[51]}$ The essential oil profile of $S$. officinalis defined by the ISO 9909 was as follows; $\alpha$-thujone (18\%-43\%), $\beta$-thujone (3\%-8.5\%), 


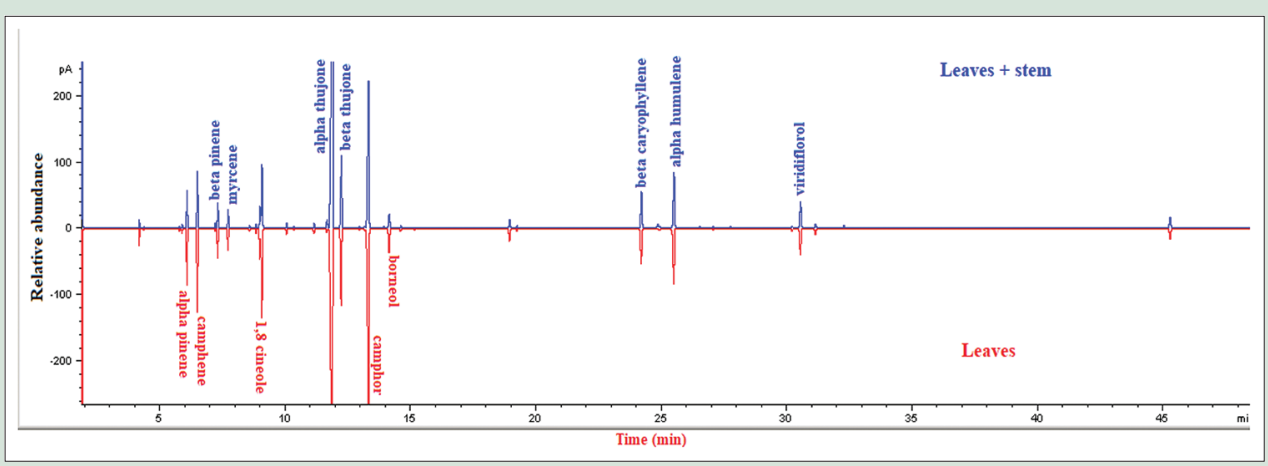

Figure 4: The analysis of Salvia officinalis essential oil from leaves + stem and only from leaves, the mirror image of gas chromatography with a flame ionization detector analysis with the relative abundance of volatile compounds against retention time

camphor $\quad(4.5 \%-24.5 \%), \quad 1,8$-cineole $\quad(5.5 \%-13 \%), \quad \alpha$-humulene $(0 \%-12 \%)$, camphene $(1.5 \%-7 \%)$, and $\alpha$-pinene $(1 \%-6.5 \%) .{ }^{[52]}$ The chromatographic analyses of our extracts were consistent with these values, indicating that oils produced using the variety of S. officinalis and the procedures which we used would be suitable for international trade.

\section{CONCLUSION}

The Soxhlet method was more efficient in extracting phenolic compounds as compared to sonic extraction, and of the three methods compared, SX can be considered the best extraction method for the preparation of phenolic extracts from S. officinalis. However, sonic extraction of S. officinalis in methanol was comparable to SX concerning intensity and diversity of phenolic acids and flavonoids. Hence, sonic extraction at low temperatures with significantly less time and solvent consumption was found to be suitable for large-scale preparation of phenolic compounds. UHPLC-ESI-QTOF-MS methodology for the analysis proved to be very efficient in the identification and characterization of targeted and untargeted phenolic compounds present in the S. officinalis extract. However, there is substantial scope to investigate more deeply a large number of yet-to-be-unidentified phenolic compounds present in S. officinalis. The lower temperature, more gentle sonic extraction may be found advantageous for the efficient recovery of a larger number of novel compounds. Essential oil profiling through GC-FID in the present study revealed the presence of 38 different terpenoid compounds. It would be fruitful to characterize $S$. officinalis essential oil by mass chromatographic techniques in the future.

\section{Acknowledgements}

Special thanks to Soil Technologies Corp., Fairfield for funding the research; Health Research Institute, Fairfield, Iowa and Amrita Aromatherapy Inc., Fairfield, Iowa for providing the facility to analyze the samples.

\section{Financial support and sponsorship}

Soil Technologies Corp., Fairfield, Iowa.

\section{Conflicts of interest}

There are no conflicts of interest.

\section{REFERENCES}

1. Sharma Y, Fagan J, Schaefer J. Ethnobotany, phytochemistry, cultivation and medicinal properties of garden sage (Salvia officinalis L.). J Pharm Phytochem 2019;8:3139-48.

2. Ghorbani A, Esmaeilizadeh M. Pharmacological properties of Salvia officinalis and its components. J Tradit Complement Med 2017:7:433-40.
3. Hamidpour M, Hamidpour R, Hamidpour S, Shahlari M. Chemistry, pharmacology, and medicinal property of sage (Salvia) to prevent and cure illnesses such as obesity, diabetes, depression, dementia, lupus, autism, heart disease, and cancer. J Tradit Complement Med 2014;4:82-8.

4. Lopresti AL. Salvia (sage): A review of its potential cognitive-enhancing and protective effects. Drugs R D 2017;17:53-64.

5. Lu Y, Foo LY. Polyphenolics of Salvia: A review. Phytochemistry 2002;59:117-40.

6. Neagu E, Paun G, Radu GL. Chemical composition and antioxidant activity of Salvia officinalis concentrated by ultrafiltration. Rom Biotechnol Lett 2014;19:9203-11.

7. Kamatou P, Viljoen A, Steenkamp P. Antioxidant, anti-inflammatory activities and HPLC analysis of South African Salvia species. Food Chem 2009;119:684-8.

8. Khiya Z, Hayani M, Gamar A, Kharchouf S, Berrekhis F, Bouzoubae A, et al. Valorization of the Salvia officinalis L. of the Morocco bioactive extracts: Phytochemistry, antioxidant activity and corrosion inhibition. J King Saud Univ Sci 2019;31:322-5.

9. Brglez Mojzer E, Knez Hrnčič M, Škerget M, Knez Ž, Bren U. Polyphenols: Extraction methods, antioxidative action, bioavailability and anticarcinogenic effects. Molecules 2016;21. pii: E901.

10. Azwanida NN. A review on the extraction methods use in medicinal plants principle, strength and limitation. Med Aromat Plants 2015;4:3-8.

11. Vinatoru M. An overview of the ultrasonically assisted extraction of bioactive principles from herbs. Ultrason Sonochem 2001;8:303-13.

12. Li H, Yao W, Liu Q, Xu J, Bao B, Shan M, et al. Application of UHPLC-ESI-Q-TOF-MS to identify multiple constituents in processed products of the herbal medicine ligustri lucidi fructus. Molecules 2017;22. pii: E689.

13. Ghisoni S, Chiodelli G, Rocchetti G, Kane D, Lucini L. UHPLC-ESI-QTOF-MS screening of lignans and other phenolics in dry seeds for human consumption. J Funct Foods 2017;34:229-36.

14. Silva-Flores PG, Pérez-López LA, Rivas-Galindo VM, Paniagua-Vega D, Galindo-Rodríguez SA, Álvarez-Román R. Simultaneous GC-FID quantification of main components of Rosmarinus officinalis L. and Lavandula dentata essential oils in polymeric nanocapsules for antioxidant application. J Anal Methods Chem 2019;2019:2837406.

15. Tandon S, Rane S. Decoction and hot continuous extraction techniques. In Handa SS, Khanuja SP, Longo G, Rakesh DD, editors. Extraction Technologies for Medicinal and Aromatic Plants. Trieste Italy: International Centre for Science, United Nations Industrial Development Organization; 2008. p. 93-106.

16. Adams RP. Identification of Essential Oil Components by Gas Chromatography/ Mass Spectrometry. $4^{\text {th }}$ ed. Illinois: Allured Publishing Corporation; 2017.

17. Panse VG, Sukhatme PV. Statistical Methods for Agricultural Workers. India: ICAR Publications; 1985.

18. Pandey A, Tripathi S. Concept of standardization, extraction and pre phytochemical screening strategies for herbal drug. J Pharmacogn Phytochem 2014;115:115-9.

19. Martins N, Barros L, Santos-Buelga C, Henriques M, Silva S, Ferreira IC. Evaluation of bioactive properties and phenolic compounds in different extracts prepared from Salvia officinalis L. Food Chem 2015;170:378-85.

20. Dent M, Kovacevic DB, Bosiljkov T, Dragovic-Uzelac V. Polyphenolic composition and antioxidant capacity of indigenous wild dalmatian sage (Salvia officinalis L.) Croat Chem Acta 2017;90:451-9

21. Dragovic-Uzelac V, Garofulic IE, Jukic M, Penic M, Dent M. Microwave-assisted extraction of sage polyphenols. Food Technol Biotechnol 2012;50:377-83.

22. Zimmermann BF, Walch SG, Tinzoh LN, Stühlinger W, Lachenmeier DW. Rapid UHPLC determination of polyphenols in aqueous infusions of Salvia officinalis 
L. (sage tea). J Chromatogr B Analyt Technol Biomed Life Sci 2011;879:2459-64.

23. Hamrouni-Sellmani I, Rahali FZ, Rebey IB, Bourgou S, Limam F, Marzouk B. Total phenolics, flavonoids, and antioxidant activity of sage (Salvia officinalis L.) plants as affected by different drying methods. Food Bioprocess Technol 2013;6:806-17.

24. Li H, Pordesimo L, Weiss J. High intensity ultrasound - Assisted extraction of oil from soybeans. Food Res 2004;37:731-8.

25. Do QD, Angkawijaya AE, Tran-Nguyen PL, Huynh LH, Soetaredjo FE, Ismadji S, et al. Effect of extraction solvent on total phenol content, total flavonoid content, and antioxidant activity of Limnophila aromatica. J Food Drug Anal 2014;22:296-302.

26. Kontogianni VG, Tomic G, Nikolic I, Nerantzaki AA, Sayyad N, Stosic-Grujicic S, et al. Phytochemical profile of Rosmarinus officinalis and Salvia officinalis extracts and correlation to their antioxidant and anti-proliferative activity. Food Chem 2013;136:120-9.

27. Qiang Z, Ye Z, Hauck C, Murphy PA, McCoy JA, Widrlechner MP, et al. Permeability of rosmarinic acid in Prunella vulgaris and ursolic acid in Salvia officinalis extracts across Caco-2 cell monolayers. J Ethnopharmacol 2011;137:1107-12.

28. Kumar S, Singh A, Kumar B. Identification and characterization of phenolics and terpenoids from ethanolic extracts of Phyllanthus species by HPLC-ESI-QTOF-MS/MS. J Pharm Anal 2017;7:214-22.

29. Madala NE, Piater L, Dubery I, Steenkamp P. Distribution patterns of flavonoids from three Momordica species by ultra-high performance liquid chromatography quadrupole time of flight mass spectrometry: A metabolomics profiling approach. Rev Bras Farmacogn 2016;26:507-13.

30. Mercolini L, Protti M, Saracino MA, Mandrone M, Antognoni F, Poli F. Analytical profiling of bioactive phenolic compounds in argan (Argania spinosa) leaves by combined microextraction by packed sorbent and LC-DAD-MS/MS. Phytochem Anal 2016;27:41-9.

31. Lee SH, Kim HW, Lee MK, Kim YJ, Asamenew G, Cha YS, et al. Phenolic profiling and quantitative determination of common sage (Salvia plebeia $\mathrm{R}$. Br.) by UPLC-DAD-QTOF/MS. Eur Food Res Technol 2018;244:1637-1646.

32. Lim H, Son KH, Chang HW, Bae K, Kang SS, Kim HP. Anti-inflammatory activity of pectolinarigenin and pectolinarin isolated from Cirsium chanroenicum. Biol Pharm Bull 2008;31:2063-7.

33. Patel K, Gadewar M, Tahilyani V, Patel DK. A review on pharmacological and analytical aspects of diosmetin: A concise report. Chin J Integr Med 2013;19:792-800.

34. Wang J, Xu J, Gong X, Yang M, Zhang C, Li M. Antioxidative phenolic compounds from sage (Salvia officinalis). J Agric Food Chem 1998;46:4869-73.

35. Cvetkovikj I, Stefkov G, Acevska J, Stanoeva JP, Karapandzova M, Stefova M, et al. Polyphenolic characterization and chromatographic methods for fast assessment of culinary Salvia species from South East Europe. J Chromatogr A 2013;1282:38-45.

36. Lu Y, Foo LY. Rosmarinic acid derivatives from Salvia officinalis. Phytochem 1999:51:91-4.

37. Dhanani T, Shah S, Gajbhiye NA, Kumar S. Effect of extraction methods on yield, phytochemical constituents and antioxidant activity of Withania somnifera. Arab J Chem 2017;10:1193-99.

38. Zhang QW, Lin LG, Ye WC. Techniques for extraction and isolation of natural products: A comprehensive review. Chin Med 2018;13:20.

39. Dhawan D, Gupta J. Comparison of different solvents for phytochemical extraction potential from datura metel plant leaves. Int $\mathrm{J}$ Biol Chem 2017; 11:17-22.

40. Osmic S, Begic S, Micic V. The effect of concentration of methanol as a solvent on the antioxidative activity of sage extract. In: Karabegovic I, editor. New Technologies, Development and Application. Vol. 42. Cham: Springer; 2019

41. Abu-Darwish MS, Cabral C, Ferreira IV, Gonçalves MJ, Cavaleiro C, Cruz MT, etal. Essential oil of common sage (Salvia officinalis L.) from Jordan: Assessment of safety in mammalian cells and its antifungal and anti-inflammatory potential. Biomed Res Int 2013;2013:538940.

42. Porte A, Godoy RL, Maia-Porte LH. Chemical composition of sage (Salvia officinalis L.) essential oil from the Rio de Janeiro State (Brazil). Rev Bras Plantas Med 2013;15:438-41.

43. Dhifi W, Bellili S, Jazi S, Bahloul N, Mnif W. Essential oils' chemical characterization and investigation of some biological activities: A critical review. Medicines (Basel) 2016;3. pii: E25

44. Baj T, Ludwiczuk A, Sieniawska E, Skalicka-Woźniak K, Widelski J, Zieba K, et al. GC-MS analysis of essential oils from Salvia officinalis L.: Comparison of extraction methods of the volatile components. Acta Pol Pharm 2013;70:35-40.

45. Khedher MR, Khedher SB, Chaieb I, Tounsi S, Hammami M. Chemical composition and biological activities of Salvia officinalis essential oil from Tunisia. EXCLI J 2017;16:160-73

46. Hussein SA, Hussein MS, Gendy AS, Tkachenko KG. Quality of sage (Salvia officinalis L.) essential oil grown in Egypt. Int J Plant Sci Ecol 2015;1:119-23.

47. Walch SG, Tinzoh LN, Zimmermann BF, Stühlinger W, Lachenmeier DW. Antioxidant capacity and polyphenolic composition as quality indicators for aqueous infusions of Salvia officinalis L. (sage tea). Front Pharmacol $2011 ; 2: 79$.

48. Pelkonen O, Abass K, Wiesner J. Thujone and thujone-containing herbal medicinal and botanical products: Toxicological assessment. Regul Toxicol Pharmacol 2013;65:100-7.

49. Radulescu V, Chiliment S, Oprea E. Capillary gas chromatography-mass spectrometry of volatile and semi-volatile compounds of Salvia officinalis. J Chromatogr A 2004;1027:121-6.

50. Craft JD, Satyal P, Setzer WN. The chemotaxonomy of common sage (Salvia officinalis) based on the volatile constituents. Medicines (Basel) 2017;4. pii: E47.

51. Hussain A, Anwar F, Iqbal T, Bhatti I. Antioxidant attributes of four lamiaceae essential oils. Pak J Bot 2011;43:1315-21.

52. American National Standards Institute. ISO 9909. Oil of Dalmatian Sage (Salvia officinalis L). New York USA: American National Standards Institute; 1997 Available from: https://www.iso.org/standard/17791.html. [Last accessed on 2019 Nov 25]. 